\title{
Erratum to: Chemical Basis of Carbon Fixation Autotrophic Paleometabolism
}

\author{
S. A. Marakushev ${ }^{a, *}$ and O. V. Belonogova ${ }^{a, * *}$ \\ ${ }^{a}$ Institute of Problems of Chemical Physics, Russian Academy of Sciences, Chernogolovka, Moscow region, 142432 Russia \\ *e-mail:marak@cat.icp.ac.ru \\ **e-mail: ovbel@icp.ac.ru
}

Received November 12, 2021; revised November 12, 2021; accepted November 12, 2021

DOI: $10.1134 / \mathrm{S} 1062359021450018$

The article "Chemical Basis of Carbon Fixation Autotrophic Paleometabolism", written by S.A. Marakushev and O.V. Belonogova, was originally published electronically in Springer-Link on 20 September 2021 without Open Access. After publication in volume 48, issue 5, pages 519-529 the authors decided to make the article an Open Access publication. Therefore, the copyright of the article has been changed to (C) The Author(s) 2021 and the article is forthwith distributed under the terms of a Creative
Commons Attribution 4.0 International License (http://creativecommons.org/licenses/by/4.0/, CC BY), which permits use, duplication, adaptation, distribution and reproduction of a work in any medium or format, as long as you cite the original author(s) and publication source, provide a link to the Creative Commons license, and indicate if changes were made.

The original article can be found online at https://doi.org/10.1134/S1062359021050095 